Article

\title{
Advocating for a More Relational and Dynamic Model of Participation for Child Researchers
}

\author{
Christina R. Ergler \\ Department of Geography, University of Otago, 9056 Dunedin, New Zealand; E-Mail: Christina.Ergler@otago.ac.nz
}

Submitted: 31 March 2017 | Accepted: 23 August 2017 | Published: 26 September 2017

\begin{abstract}
Primary school children participating as researchers has become a moral obligation to meet the goal of children's participation rights. Yet, critical voices rarely question the ethical and practical implications of turning young children into mini-clones of adult researchers. While enabling and constraining aspects of participatory methods and inherent power issues per se are widely discussed, adult researchers still seem to struggle to critically engage with celebratory accounts of children as researchers. In particular, the practical obligations, ethical challenges and tensions that impact on primary school children's research experiences, are underexplored. Findings from two projects on play, which engaged children as active researchers, suggest that more attention needs to be paid to the messy realities of becoming and being a child researcher. In particular, researchers should be more attuned to children's capabilities and the ethical hurdles for child and adult researchers. This article argues therefore for a more dynamic, meaningful and realistic model of participation, that speaks to the messy realities of becoming and being a child-researcher. In other words, the article questions the dominant orthodoxy of children as researchers as the 'gold standard' of participatory research with children.
\end{abstract}

\section{Keywords}

children; ethics; participation; research

Issue

This article is part of the issue "Promoting Children's Participation in Research, Policy and Practice", edited by Jo Aldridge (Loughborough University, UK).

(C) 2017 by the author; licensee Cogitatio (Lisbon, Portugal). This article is licensed under a Creative Commons Attribution 4.0 International License (CC BY).

\section{Introduction}

Employing young people as researchers is currently in vogue. In 2016, I attended the "Children and Young People in a Changing World: Action, Agency and Participation" conference at Liverpool Hope University (Merryweather, 2016). A workshop and several sessions were devoted to young people as researchers. The majority of presenters celebrated co-investigation as the 'best' partnership between children and adults. Implicitly, there was a strong message to follow their example and involve child researchers in studies to overcome uneven power relations in the traditional adult-child research relationship, unveil children's most 'authentic' voice, and empower children in all areas of their life (see also Beazley, Bessell, Ennew, \& Waterson, 2009; Porter et al., 2010). Nairn, Higgins and Sligo (2007, p. 2) have already highlighted that the use of youth as researchers is "often underpinned by unspoken assumptions that involving children and young people as researchers is a good thing in and of itself". In other words, employing children as researchers is viewed as morally and ethically superior compared to adults being the sole drivers of a study. Critical voices are a whisper in this context (Alderson, 2012; Holland, Renold, Ross, \& Hillman, 2010; Kim, 2016; Wyness, 2013).

In this article, I contend that the relative silence of critical voices can be attributed to the idealisation of child researchers and more critique concerning children as researchers is warranted. In particular, I argue that more attention needs to be paid to messy realities of being and becoming a child researcher. Drawing on two participatory research projects in which children aged $8-10$ years became researchers to examine sea- 
sonal and water-related play practices, I advocate for a more dynamic approach that responds to children's experiences and their competencies. Child and adult researchers should constantly negotiate their inclusion and roles in the entire cycle of a research project in order to develop more realistic and meaningful participation for children. In other words, this article explicitly questions the dominant orthodoxy of children as researchers as the 'gold standard' of participatory research with children.

The article begins with a brief reflection on the role participatory methodologies have historically played in employing children as researchers and moves on to introduce the two research projects on which the article is based: 'seasonal play' and 'water \& play'. I discuss the different roles children took in the two studies on play and their associated ethical complexities before I conclude the article with two suggestions for further discussion.

\section{The Framing of Children as Researchers}

\subsection{The Development of Employing Children as Researchers}

At the beginning of the 1990s researchers, informed by postmodern and feminist theories, increasingly highlighted children as experts on their own lives. They placed children as competent, knowledgeable 'beings in the here and now' rather than as uninformed and 'becoming-adults' (Christensen, 2000; Holloway \& Valentine, 2000; James, Jenks, \& Prout, 1998). These developments have been further fueled by the United Nations Convention on the Rights of the Child, which requires researchers and policy makers to consult with children on issues concerning their life and to treat them as active citizens. As a consequence, seeing children as social actors in their own right has led to children's more active involvement in research projects and shifted and complicated how participation is framed (Horgan, Forde, Martin, \& Parkes, 2017; Powell, Fitzgerald, Taylor, \& Graham, 2012; Skelton, 2007).

Children's participation in research became both a research tool and an aim for researchers and the term 'participation' began to carry a double meaning (Gallacher \& Gallagher, 2008). Firstly, the term covers children's involvement as active participants in a wide spectrum of child-friendly, child-centred or child-led participatory methods (e.g., photo-voice, drawing exercises, radio shows) (Barker \& Weller, 2003; Porter et al., 2012; van Blerk \& Kesby, 2013). Secondly, increasing children's participation in research became an aim and often unspoken moral and ethical requirement to comply with the United Nations Convention on the Rights of the Child, to recognise children as current citizens and capable social actors (Gallacher \& Gallagher, 2008). Concepts of children's rights, justice and empowerment are a central part of these discussions and frame children's participation in research and wider societal issues (Graham, Powell, Taylor, Anderson, \& Fitzgerald, 2013; Horgan et al., 2017; Lundy \& McEvoy, 2012). As a consequence, many research projects have moved from adult-centred to child-led studies in the search for child-friendlier methods and ways to increase children's voice in research and society (Gallacher \& Gallagher, 2008; Porter et al., 2012; Wyness, 2013). Therefore, it is not surprising that debates around the ethics of care in research relationships and how children value and experience their participation began to emerge (Blazek, Smith, Lemešová, \& Hricová, 2015; Hadfield-Hill \& Horton, 2013; Pinter \& Zandian, 2012). However, researchers also began to look at children's voices in research within the complexities of their status as 'beings and becomings' and the relational nature of children's lives (Leonard, 2016; Nielsen, 2016; Wyness, 2013). Despite ongoing discussions about whose voice is heard (Jones, 2003; Mills, 2017; Philo, 2003; Spyrou, 2015; Thorne, 2002), children as researchers seems to remain the latest development on the participation front to reveal children's most authentic voice.

Historically, adult researchers employing children as researchers saw their employment as a means through which to showcase children's recognition as current citizens and capable social actors. Another motivator to embark on such research was that adult researchers believed that child researchers gained more authentic insights into children's life worlds than adults (Freeman \& Mathison, 2009; Kim, 2016; Nairn et al., 2007). Involving children as co-investigators or so called peer researchers in studies has taken many forms. Adult researchers have included children of all ages, although the dominant cohort usually consists of teenagers and young adults, in the design stage of projects (Kellett, 2011), data collection practices (Nairn et al., 2007; Porter et al., 2010; Schäfer \& Yarwood, 2008) and analysis (Coad \& Evans, 2008; Nind, 2011) as well as in the dissemination of findings (Kellett, 2004). These studies-which follow on from the example of others (see for example Alderson, 2001; Boocock, 1981; Oldfather, 1995)-have contributed to the popularisation of children as researchers. While only a few studies have worked with children or young people throughout the entire cycle of a project (Cahill, 2004; Kellett, 2011; McLaughlin, 2005) the ones that do tend to be small scale or train a well selected number of teenagers or young adults in research practices and procedures often on a one-on-one basis (Åkerström, Aytar, \& Brunnberg, 2015; Fleming \& Boeck, 2012; Kellett, 2005; Kim, 2016; Marsh, 2012; Porter et al., 2010).

When children become researchers their participation often remains piecemeal and subject to an adult agenda. For example, children and young people are often only employed for the data collection phase (Nairn et al., 2007; Porter et al., 2010; Schäfer \& Yarwood, 2008). Although researchers often not explicitly state reasons for this practice, issues around logistics, adequate pay and time commitment as well as data confidentiality and quality of analysis (e.g., potential identifiability of participants despite anonyminisation) have been mentioned 
(Fleming \& Boeck, 2012; Holland et al., 2010; Nind, 2011), Nonetheless, this overall limited involvement leaves little room for children's own interests, ideas and motivations to be integrated in a project as researchers, because they are positioned to respond to adult set tasks. It seems the focus on children's meaningful, genuine and authentic participation once proposed by Hart (2008) seems to have faded when we invite children as researchers on project (Ergler, 2015).

\subsection{Endorsing Children as Researchers and its Challenges}

In the introduction, I already highlighted that the employment of children as researchers is generally seen as a good "thing in and of itself" (for more details see Ergler, 2015; Nairn et al., 2007). The majority of presenters at the 2016 Liverpool conference (Merryweather, 2016) seem to have celebrated young people as researchers in various research stages as the gold standard of participatory research. Similarly, Kim (2016) highlights that research by children is on the rise as it is currently fashionable and encompasses normative and methodological advantages (see also 2.3). Therefore, it is not surprising that Alderson (2012) critiqued Beazley et al. (2009) for not going far enough in their thinking on children's participation in research. Alderson suggests inclusion of young people as co-authors to present a "more balanced multi-sided account of rights-respecting research". All in all, increasing the degree of children's participation in research per se seems to have been more important than their meaningful participation (see also Horgan et al., 2017; Kim, 2016; Pinter \& Zandian, 2012). Priority has been placed on the rhetoric to include children as coresearchers and co-producers of knowledge from design to dissemination, rather than on the relevance of such activities (e.g., co-authorship) for children. Whether children enjoy a particular research stage or whether the research activities are meaningful to them is not discussed. The continuing involvement of children as researchers is surprising as evidence begins to emerge of logistical and procedural issues during the research process (Fleming, 2012; Nairn et al., 2007; Porter et al., 2010). For example, in Schäfer and Yarwood's (2008) or Nairn and colleagues' (2007) study, some youth peer researchers were unable to establish rapport with participants or policed their participation due to a mismatch of their subcultural capitals (e.g., education, manors) and misunderstanding of the role of a researcher. These misunderstandings impacted directly on the quality of data collected. Other researchers highlight the issue of payment in relation to inflexible payment systems of institutions (e.g., payrolls, timesheets, GST receipts needed) and real time commitment for adult and child researchers (Coad, 2012; Fleming \& Boeck, 2012; Nairn et al., 2007; Porter et al., 2010). The scheduling of research activities and the social and economic costs of participation (e.g., dealing with being bullied, disregarding social conventions, double bur- den of household chores and conducting research, transportation) is also mentioned as an important problem (Coad \& Evans, 2008; Nairn et al., 2007; Porter et al., 2010). Others focus more on whether children can really be experts about the lives of other children (Tisdall, 2012). Nonetheless, the critical debates focus more on logistical challenges when children are employed as researchers rather than their meaningful participation or the messy realities of becoming and being a child researcher. Given all these issues and challenges, why do researchers continue to employ children as researchers?

\subsection{Why Do Adult Researchers Invite Children as Researchers on Projects?}

Researchers (e.g., Kim, 2016; Nairn et al., 2007; Porter et al., 2010) identify three intertwined practical and methodological advantages for employing children as researchers that are closely related to the underpinning principles of "The International Charter for Ethical Research Involving Children", namely respect, benefit and justice (Graham et al., 2013). Firstly, co-investigative projects intend to enhance the ethical dimension of respect by supporting children's active participation as current and not future citizens in societal matters (Kim, 2016; UNICEF, 1995). Secondly, researchers believe co-investigative studies teach children invaluable skills (Hampshire et al., 2012; Kellett, 2011) and produce 'better' research outcomes as child-researchers are closer to their peers (Coad, 2012; Nespor, 1998). Nonetheless, it has to be noted that the claim of producing better or at least different data has not been systematically assessed (Holland et al., 2010; Kim, 2016). Third, children's employment as researchers has been celebrated as a way to overcome some of the moral and ethical hurdles of nonparticipatory research, especially the issue of power hierarchies in the adult-child research relationships (Ergler, 2015; Graham et al., 2013; Matthews, 2001). This is centred on the idea that in co-investigative projects the decision making power on research design and procedures previously solely held by the adult researchers should be shared with child researchers (Cahill, 2004; Walsh, 2016). Adults and children thus, theoretically 'share' power in co-investigative projects gaining 'authentic' knowledge with and by child researchers. Justice as a principle in research then arises through the respectful dialogue between adult and child researchers. In other words, employing children as researchers can be seen as a moral and ethical requirement to seize the double meaning of participation underpinned by principles of respect, benefit and justice.

Despite these noble underpinnings for the employment of children as researchers, I question in this article the dominant orthodoxy of children as researchers as the 'gold standard' of participatory research with children. Therefore, my intention in the remainder of this piece is to argue for the need to develop a more dynamic and relational model of participation that speaks to the 
messy realities of becoming and being a child researcher by highlighting some of the ethical and practical complexities that arose in my two studies on play. I conceptualise the terms 'being and becoming' deliberately in a twofold way. First, the term literally encapsulates the process of becoming and then being a child researcher. In this way, I emphasize that children are social actors who actively construct their research world and at the same time can increase their competencies through a scaffolded learning process (becoming researchers). However, such a conceptualisation also entails a reciprocal relationship between child and adult researchers as well as between child and child researchers. Adult researchers not only familiarise children with research practices, but also child researchers teach their peers and adult researchers different ways of looking at the world, the research process and outcomes. Adult and child competencies complement each other, but can also increase over time and through learning from each other. Second, child researchers are not operating in a vacuum. They have a past, present and future. Such a conceptualisation allows to incorporate that children and their future self are shaped by their past and present experiences in society and research. In other words, this conceptualisation views children as "being present and future agents of their present and future lives" (Uprichard, 2008).

\section{A Brief Introduction to the Two Projects 'Seasonal Play' and 'Water \& Play'}

\subsection{The Seasonal Play Project}

The first project 'seasonal play' was located in Auckland, New Zealand, and part of a larger study that compared the seasonal play practices of primary school children (aged 8-10 years) in the coastal suburb of Beach Haven and the central city of Auckland. The overall project was inspired by feminist approaches (Rose, 1997) and in particular the debate on children as competent actors who are experts on their life (James \& Prout, 1997). My aim was to bring children's experiences and their own voices of playing and being active in different seasons to debates on declining activity and increasing obesity rates (Ergler, Kearns, \& Witten, 2013, 2016). Although the two Auckland study areas were similar in their socioeconomic composition, they differed in the built environment. The suburb was characterised by detached houses with gardens, while the central city children lived in apartments with limited access to outdoor spaces. However, in both study areas children had access to small green spaces and bigger parks with sports fields and playgrounds within walking distance. This large project was adult led and invited children to draw maps of their seasonal play destinations and share their play experiences in semi-structured interviews. However, children from both study areas were interested in the study beyond the adult set tasks that aimed to gain insights in their differing seasonal play worlds. For example, I noted in my di- ary that Rosie from Beach Haven has asked me why they "can't meet the city kids". She told me that she and her friends had a chat on the playground wondering what and where children in the city play. This and other discussions led to the development of the project 'seasonal play'. The 'seasonal play' project aimed to bring all interested children from both study areas together to satisfy their curiosity in the large research project in a child centred way.

In both study areas, the ten (three from the city and seven from Beach Haven) interested children were invited to take the non-local children on a child-guided tour around their neighbourhood. 'Local' children were instructed to be the advocate for their neighbourhood and show the 'visitors' fun and boring neighbourhood activities for summer and winter, while the 'non-local' children were invited to adopt a researcher role and question the local children like a 'journalist' about their seasonal play practices, preferences and neighbourhood experiences during the walk (see also Acharya, 2010). To capture the walks, which took place on two Saturdays in December 2010 (summer in New Zealand), children were offered a digital camera, voice recorder and a GPS tracker, but they could decide how much they utilised this equipment or if they wanted to use it at all. The novelty in this approach was that children tailored their neighbourhood walk to someone the same age, moving the adult researcher and field assistants (four female and one male) as observers into the background. Children became de facto researchers leading the neighbourhood walk and through their analysis of the anonymised data collected during the adult-let study (for a more detailed discussion see Ergler, 2011).

\subsection{The Water and Play Project}

The positive experiences during the 'seasonal play' project and children's enthusiasm to be involved in the project as researchers instigated the second study 'water \& play'. I invited nine and ten year olds from a coastal suburb in Dunedin, New Zealand, to become co-investigators in all research stages supported by one male research assistant. In this second study, the research agenda was not pre-set and developed over the course of ten biweekly two hour 'research club' sessions after school hours (plus three days of data collection during school holidays) in 2013. I planned to gain insights into children's wellbeing in and around water through participant observation. My first overarching aim, however, was that children should benefit through their participation. The research club was designed to be fun and playful. New friendships could develop or old ones deepened as children from different class rooms attended the sessions. The research club sessions provided enough time to play and get to know each other outside a class room setting. Moreover, children could pick up various skills during these sessions (e.g., critical thinking and problem solving, developing skills and confidence in speaking). My second 
overarching aim was to provide an arena for a collaborative research environment by supporting children to conduct their own group project driven by their curiosities and competencies. In order to achieve this goal, children acquired diverse research skills ranging from developing research questions to being an ethical researcher as well as ways of analysing and disseminating findings (see also Kellett, 2005). I believe children should be exposed to and trained in research before they embark on their own project. For me, such practice signals fairness and respect for children's competencies and their role as social actors.

Children decided democratically on the project they wanted to carry out and how. They opted for finding out "what makes playing on the beach so popular and why is it so much fun", utilising an auto-ethnographic approach (see also Liggins, Kearns, \& Adams, 2013). They had limited interest in involving any study participants beyond their group of ten; they were adamant about not sharing the privilege of being part of the study with children outside the 'research club'. Research activities involved playing at the local rocky and sandy beach, which were located side-by-side in this suburb. The next stage was an individual reflection in the form of a digital poster. This was followed by a mapping exercise to physically locate "fun things to do at the beach". Later in the process ten brief videos were developed and staged by the children "about what [they] like doing at the beach and why". These videos show for example the children playing cricket, drawing in the sand, and collecting stones and treasures at the beach. To capture their play experiences during the research process, children utilised their individual Ipad, pens, paper, notebooks, GPS trackers and a video camera provided by the adult researcher's institution. The project finished with an evening during which they presented their findings and videos to parents, teachers, local politicians and other community members.

In the following Section 4, I synthesise the dominant themes occurring in both projects in order to support my argument that more attention needs to be paid to the messy realities of becoming and being a child researcher. In particular, I reflect on and exemplify children's shifting roles in the projects and the complex ethical research realities during the course of both projects. Children are referred to by pseudonyms.

\section{Findings}

\subsection{Merging the Roles of Being a Participant, Researcher and Play Mate}

Participatory research with children puts the emphasis on children's genuine participation in research. Although adult researchers lead the studies, they try to understand children's life worlds collaboratively with children in order to improve their lives. In contrast to solely adultled research that is more outcome focused, participatory research focuses on children's experience during the research process. Nonetheless, the practice of research exists around pre-defined roles (Goffman, 1959; Punch, 2002). The way research is conducted has been normalised over the years. Traditionally, researchers take on an active role during the research process by leading activities to gain knowledge. Participants are often passive, because they are expected to follow an unspoken rule of responding adequately to pre-set tasks (e.g., semistructured interviews). No matter how participatory the research is, the norm is that all parties involved should perform the roles agreed on. However, reflecting on the projects 'seasonal play' and 'water \& play', theory and practice differs. The reality was messier.

When children become researchers, the lines between the distinct roles of a researcher and participant become blurred. On the one hand, given how research has been institutionalised, children are not only researchers, but also participants in studies that conform with institutional ethic guidelines. On the other hand, everyday activities such as play creep into the research process unexpectedly (see also Blazek et al., 2015). While children do not necessarily leave the formal research space and wander off to a playground, they nonetheless, easily and happily move between the roles of playmate, participant and researcher.

To move more fully into the role of a researcher during the 'seasonal play project', some children proudly told me that they decided to carry a GPS unit, digital camera and voice recorder for capturing the walk. Likewise, it became the norm for the 'water \& play' researchers to carry the Ipads and other equipment to the beach "just in case" they wanted to record an activity or experience. The equipment, as children from both projects declared, became a signifier for being a "proper researcher". However, utilising the equipment seemed at times artificial and more a hindrance to also engaging in the play they wanted to capture (e.g., playing piano in a shop, climbing a tree, playing cricket, drawing on the sand, collecting "treasures" at the beach). Children quickly realised that capturing and participating at the same time in the play activity did not work out as they planned at the outset of the study. So, they took mental notes of their experiences to write them, for example, down at a later stage (see Figure 1 for an example of a play reflection). However, some children still wanted to capture the activities on camera. So, they included the adult observers in the research process and told them what and how they wanted certain activities recorded. Children reflected on the feasibility of the equipment to capture their play and creatively overcame the obstacles they encountered. Children were participants, researchers and play-mates at the same time.

Nonetheless, their role as a child researcher was less explicit during the walk in the seasonal play project. The playful exploration of the neighbourhood seemed to have more prominence for the city and Beach Haven children. Children were more engaged in sharing and enjoying their play spaces in both locations (city and suburb), 
rather than documenting their play and the reasons why they enjoy these play spaces during different seasons. However, children still took their role as researcher seriously. For example, two boys, who found it difficult to formally capture their neighbourhood walk in the seasonal play project, took the project in their own hands on returning to the community hall. They reflected unprompted on the walk using one of the voice recorders (which I only discovered after listening to the tapes) mimicking the interview style of a reporter. The following is an extract from this interview.

Michael: This is Michael (Last name) here as a reporter and I would like to ask you a few questions, okay?

Josh: Okay.

Michael: What was the favourite bit of the walk?

Josh: The bush walk!

Michael: Why was it your favourite bit? What made it so exciting for you?

Josh: Uhu, oho (giggles) oh the laughing side, because umm (both giggle) because Michael was a chatterbox all the time like this is one of the things.

Collecting data and being a researcher for children can have many different facets. Michael and Josh moved from being participants responding to adult tasks to initiating activities and experimenting with their role as reporter/researcher. Michael and Josh continued to 'play' researchers after the neighbourhood walk. While during the walk, play seemed to be at the forefront for an adult observer, the two boys were clearly, as subsequent events showed, already reflecting on and process- ing their play experiences. These events could be readily recalled once they slipped into the role of an interviewer and respondent. The intimate and unobserved space of the community hall allowed these two boys to reflect and capture their experiences in a playful way. They were able to communicate what mattered and was real to them (Mistry, Bignante, \& Berardi, 2016; Pinter \& Zandian, 2012) and merge academic goals with their own interests (Nind, 2011). Similarly, Anderson and Jones (2009) also observed that the material environment in which research is conducted shapes children's voices. It shapes what they are willing to share.

Correspondingly, the children in the 'water \& play' project decided to make a distinction between playing and capturing their play experiences after engaging in an informal play session testing the equipment at the beach. After reflection on the difficulties of capturing their play (see also discussion above), the children decided to go to the beach for two hours "just to play" and afterwards create a poster on their Ipads about their experiences using the diverse apps available (see Figure 1 for an example).

These examples demonstrate that children defined their role of a researcher in less orthodox ways than the normalised research practices suggest. Children moved quickly from one role into the other and back. Playing and researching collapsed (see also von Benzon's, 2015, discussion on truth in research and children's imagination); sometimes children's reflections about the research process took centre stage while at other times their thoughts were buried in play.

Children's playful engagement with research worked against the dominant practice of turning children into serious researchers (see for example Kellett, 2004). Children in the two projects replaced such an adult-centred research process with a more meaningful participatory frame: playing became part of researching and research part of playing. To be attuned to the lived realities of chil-

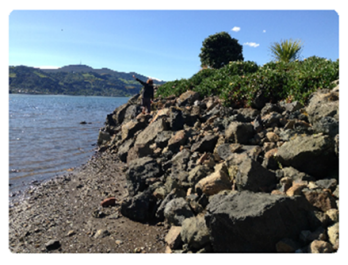

I do like to do these thing at mac bay beach because you can find stuff like interesting bits of wood, smooth worsglass and crabs

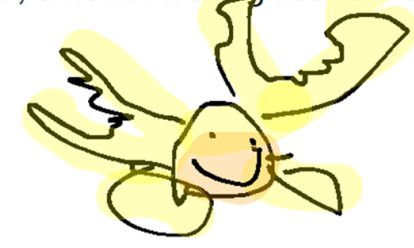

This is me on the rocks

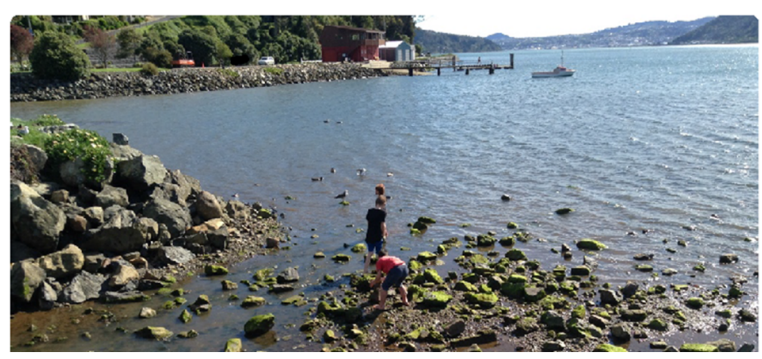

Figure 1. An excerpt of Tiki's poster. 
dren as researchers, adult researchers should be open to and encourage spontaneous and diverse research pathways and roles for children in research. Expecting all children to perform the role of an adult mini-clone researcher and be involved in all research stages leaves little room to explore their interests and capabilities. For example, one child in the water and play project dropped out half way through with the explanation that she did not enjoy learning about the research process. Likewise, two boys (Tiki and Samson) who decided after the community presentation to write the research up asked after a while whether I can simply interview them and then do the writing myself (see Ergler, 2015, for more details). Through being interviewed they could participate in the writing up process, but in a way and on a time scale that suited them better.

All these examples let me conclude that children need to find a place in the research project that is meaningful and realistic for the individual child. Finding such a place also requires to reflect on, discuss and find ways around the currently conflicting temporalities between institutional or adult timelines to design, conduct, analyse and disseminate research in a 'timely manner' and children's time scales. Children's motivations, interests and availability varies across the research cycle due to other commitments (e.g., school, sports), but also how well the task speaks to their capabilities and interests. In other words, children need to find a role that easily allows them to move between 'being' (playing) in the moment and performing (an adult like) role in research.

\subsection{Dealing with Procedural Ethics and Research Realities}

Children grasped the theoretical relationship between moral principles and ethical research procedures. Institutional ethical principles seemed to resonate well with children's intuitive ethical norms in both projects. Children from both projects talked about (represented here in Tiki and Samson's words) that "not hurting anyone's culture" or "respecting people" is important when conducting research. Children easily subscribed to "valuing people" and "not causing harm" as the backbone of sound ethical research. In reality though, conducting ethical research according to institutional expectations was more a learning process.

After the initial development of their own ethical framework in the water and play project, I slipped more formally into the 'teacher role'. I introduced through different role play exercises institutional ethical procedures on for example informed consent. The child researchers reported that the ethical values and practices discussed were "quite easy to remember" (Tiki and Samson from the water \& play project). Translating this common sense knowledge into institutional ethical protocols during research looked like an easily achievable task. But being an 'ethical researcher' was less straightforward when children, for example, piloted the methods or collected data.
Child researchers had difficulties putting the procedural ethical guidelines into practice. They understood and embodied the institutional ethical protocols during the exercises designed to familiarise them with the ethical requirements (e.g., asking permission to take a photo), but the real meaning of the ethical code of conduct expected by ethic committees remained ambiguous in the context of the research setting.

Being an ethical researcher was overwritten by many other activities in practice. However, these diverse difficulties reminded me about the need for on-going reflection to address how ethical protocols can be put into practice (see also Farrell, 2005; Gallagher, 2009; Horton, 2008; Morrow \& Richards, 1996). Children in both projects, for example, "played" with the cameras and took "funny" photos of each other or by-standers. Others forgot or felt uncomfortable asking for permission to film or take photos of people they knew well and interacted with on a daily basis. Even when children followed the standard institutional protocol and sought consent, they had difficulties dealing with "no" as an answer. For example, a group from the 'water \& play' project, who practised the institutional protocol, asked to film and interview a group of teenage boys hanging out at the local playground. When the teenagers declined, the group of child researchers turned the activity into a game and chased the teenagers across the playground. They tried to capture the teenagers' activities without permission, switching between playing and data collection. Another group in the water \& play project purposefully created a dispute at the playground over access to the swings to document a common situation for their video project. Getting 'good data' for their documentary took priority over 'not causing harm' for a participant's dispute which ended in tears. Making sense of ethical protocols and being an ethical researcher was less straightforward than the child researchers or I expected after the role play exercises. In addition, it showcases the need to move beyond current ethical discussions on issues of children's consent and representation (Alderson, 2004; Clough, Connolly, Dockett, Einarsdottir, \& Perry, 2009; Graham, Powell, \& Taylor, 2015) towards a child led ethical research frame and protocol.

Child researchers cannot be expected to immediately follow the procedural and institutional guidelines adults have developed over years. Expecting children to follow these guidelines does not engage children's intuitive moral understandings or value child researchers as co-investigators. More emphasis needs to be placed on the learning process and the co-development of a meaningful ethical approach that takes the circumstances of projects into account (Gallagher, 2008; Horton, 2008; Shaw, 2016). Moral principles and procedural ethical guidelines can only be fully implemented over time and when child and adult researchers reflect on the research process. Incorporating more reflexive practices to address the lessons children and adult researchers learn at every stage of the research cycle brings institutional 
discourses and research realities closer together. It takes time to develop, grasp and implement moral principles and procedural ethical guidelines fully. Conducting ethical research is a learning process.

\section{Conclusion}

In this article, I questioned the dominant orthodoxy of children as researchers as the 'gold standard' of participatory research with children. I argued that the majority of adult researchers champion the employment of children as researchers without paying enough attention to the messy reality of becoming and being a child researcher. I proposed to focus more on how children experience, evaluate and grapple with becoming researchers rather than on logistical challenges of payment, time commitment, quality of data or future benefits for child researchers which dominate current debates (Fleming \& Boeck, 2012; Hampshire et al., 2012; Porter et al., 2010). My goal is to complicate and contribute to discussions on what matters to children when participating in research and as active researchers (Horgan et al., 2017; Pinter \& Zandian, 2012; Smith, Monaghan, \& Broad, 2002) and more generally to debates on children's meaningful participation and their voice in research projects (see for example Horgan et al. 2017; Mills, 2017).

The intention of the article was twofold. Firstly, I wanted to show that if we value children as active researchers, more critique concerning children as researchers is warranted. The two projects showed that becoming and being a child researcher is a messy process and more complex than learning about and applying institutionalised research processes. Even when children want to learn about and engage in different stages of a research project or when they carve out their own research niche in an existing project, they define their role as researchers in less orthodox ways than simply performing the normalised roles of an adult researcher. Rather, child researchers combined playing and researching in the two projects (see also von Benzon, 2015). They conducted their research playfully, but also sought support from each other and the adult researcher to move their projects forward. In addition, they playfully taught me to reconsider what matters to them participating in research and as active researchers. Freire and others already highlighted the need to view participation in research as dialogical encounter and this should be expanded when children become researchers (Freire, 2001; Horgan et al., 2017; Weil, 1999). My findings reiterate the need to subscribe to a dynamic and relational approach in which child and adult researchers constantly negotiate their roles and the degree of involvement in research projects. Such an approach then takes into account that children participating as researchers move between 'being' (or playing) in the moment and 'becoming' researchers. In other words, the studies clearly showed that when children become researchers there is a need to pay more attention to reciprocal relationships between adult and child researchers during the research process where both can play together and learn from each other.

Secondly, I hope that these discussions lead to further conversations about children's meaningful participation as child researchers during the entire cycle of a research project. I now provide two closely linked points I consider worthy of future discussion. First, when researchers aim to walk down the path of making children partners in research projects and desire to work side by side with children to carry out research together, we should ask the questions who is the expert and for what aspects of the research? Should adult researchers be viewed as the experts for conducting research and children for revealing their life worlds? Can we really train children as researchers when it takes so long to become an adult researcher? In other words, we need to engage more firmly in discussions about whether research is expert work or if anyone can become a researcher. The studies discussed here showed that although the children were interested in becoming researchers, delving into the complexities of conducting research did not always sit comfortably with their interests or capabilities. However, I do not want to imply that children do not have the capacity to become researchers or should be denied the opportunity to become researchers. Rather, we should be less romantic about the employment of children as researchers and move away from the current idealised picture of employing children as researchers. Even when children become researchers, we cannot close our eyes from the structural constraints of conducting research with children.

These constraints are far reaching and include, but are not limited to research ethics, design and funding. For example, adult researchers still need to comply with institutional research ethic protocols and as a consequence child researchers, too (unless we question the normalised research processes per se). Adult researchers are also expected to design, conduct and disseminate research in a timely manner, but definitions of 'timely' can differ between children and adults and can depend on the availability and time commitment of child researchers. Participating in research is only one activity besides school, sports, clubs and other leisure activities children are involved in. Moreover, the current funding landscape hardly allows flexibility in the development of additional research phases, uncertain outcomes or open research designs. To move beyond rigid research expectations at the outset and the inclusion of children as researchers as an either/or approach, funding agencies could be more open to and allow flexibility to comply with children's changing and diverse interests throughout the research cycle. Similarly, I believe if we take children as social actors seriously and want to involve them in the entire research cycle we also need to train them properly in a child-centric way in research methods. They have the right to know the research background to make informed contributions as researchers. However, at the 
same time, this also means adults remain the gate keeper for research.

Second, is the employment of children as researchers simply an extension of adult let research or the gold standard of participatory research? The employment of children as researchers can be seen as answering the mandate of the United Nations Convention of the Rights of the Child and the International Charter for Ethical Research involving Children (Graham et al., 2013; UNICEF, 1995). Asking children to become researchers not only recognises their capacities and values them as current citizens, but also addresses the charter's principles of respect, benefit and justice (Graham et al., 2013). However, simply championing children's capacities as researchers can lead us away from asking critical questions about how children experience being an active researcher. For example, we should discuss more openly their participation as researchers in relation to the practical obligations, ethical challenges and tensions arising from child researchers' participation. These discussions would move debates from the logistical aspect (Fleming \& Boeck, 2012; Porter et al., 2010) towards children's more meaningful participation as active researchers. However, do we then measure their meaningful participation as child researchers from an adult centric position and whether they are capable and interested in becoming a mini clone (although this was never my intention, some might accuse the presented studies of such an adult centred view). Or do we put a child centred lens on and question the research process in its current and dominant form?

All these discussion points have at their heart enhancing children's meaningful participation in research and embracing their opportunities to become active researchers. The majority of children enjoy being researchers and are proud of their achievements and the research outcomes. Nonetheless, we need a different model of participation for child researchers. We need a more dynamic and relational model that speaks to the messy realities of becoming and being child researchers.

\section{Acknowledgements}

I like to thank the child researchers for their participation in the two studies and the four anonymous reviewers and my colleagues for their constructive and helpful feedback on earlier versions of this article.

\section{Conflict of Interests}

The author declares no conflict of interests.

\section{References}

Acharya, L. (2010). Child reporters as agents of change. In B. Percy-Smith N. \& Thomas (Eds.), A handbook of children and young people's participation: Perspectives from theory and practice. New York: Routledge. Åkerström, J., Aytar, O., \& Brunnberg, E. (2015). Intra- and inter-generational perspectives on youth participation in Sweden: A study with young people as research partners. Children \& Society, 29, 134-145.

Alderson, P. (2001). Research by children. International Journal of Social Research Methodology, 4, 139-153.

Alderson, P. (2004). Ethics, social research and consulting with children and young people. Ilford: Barnardo's.

Alderson, P. (2012). Rights-respecting research: A commentary on "The right to be properly researched: Research with children in a messy, real world". Children's Geographies, 2009, 7. Children's Geographies, 10, 233-239.

Anderson, J., \& Jones, K. (2009). The difference that place makes to methodology: Uncovering the "lived space" of young people's spatial practices. Children's Geographies, 7, 291-303.

Barker, J., \& Weller, S. (2003). "Is it fun?" Developing children centred research methods. International Journal of Sociology and Social Policy, 23, 33-58.

Beazley, H., Bessell, S., Ennew, J., \& Waterson, R. (2009). The right to be properly researched: Research with children in a messy, real world. Children's Geographies, 7, 365-378.

Blazek, M., Smith, F. M., Lemešová, M., \& Hricová, P. (2015). Ethics of care across professional and everyday positionalities: The (un)expected impacts of participatory video with young female carers in Slovakia. Geoforum, 61, 45-55.

Boocock, S. S. (1981). The life space of children. In S. Keller (Ed.), Building for women. Lexington: Lexington Books.

Cahill, C. (2004. Defying gravity? Raising consciousness through collective research. Children's Geographies, 2, 273-286.

Christensen, P. H. (Ed.) (2000). Research with children: Perspectives and practices, London: Routledge Falmer.

Clough, P., Connolly, P., Dockett, S., Einarsdottir, J., \& Perry, B. (2009). Researching with children: Ethical tensions. Journal of Early Childhood Research, 7, 283-298.

Coad, J. (2012). Involving young people as co-researchers in a photography project. Nurse Researcher, 19, 11-16.

Coad, J., \& Evans, R. (2008). Reflections on practical approaches to involving children and young people in the data analysis process. Children \& Society, 22, 41-52.

Ergler, C. (2011). Beyond passive participation: Children as collaborators in understanding neighbourhood experience. Graduate Journal of Asia-Pacific Studies, 7, 78-98.

Ergler, C. (2015). Beyond passive participation: From research on to research by children. In R. Evans, L. Holt, \& T. Skelton (Eds.), Methodological approaches. Singapore: Springer Singapore.

Ergler, C., Kearns, R., \& Witten, K. (2013). Seasonal and locational variations in children's play: Implications for wellbeing. Social Science \& Medicine, 91, 178-185. 
Ergler, C., Kearns, R., \& Witten, K. (2016). Exploring children's seasonal play to promote active lifestyles in Auckland, New Zealand. Health Place, 41, 67-77.

Farrell, A. (Ed.). (2005). Ethical research with children. Maidenhead: Open University Press.

Fleming, J. (2012). Moving to the inside: Employing young people as researchers. In J. Fleming \& T. Boeck (Eds.), Involving children and young people in health and social care research. Hoboken: Taylor and Francis.

Fleming, J., \& Boeck, T. (2012). Involving children and young people in health and social care research. Hoboken: Taylor and Francis.

Freeman, M.. \& Mathison, S. (2009). Researching children's experience. New York: Guilford Press.

Freire, P. (2001). Pedagogy of freedom: Ethics, democracy, and civic courage. New York: Rowman and Littlefield.

Gallacher, L.-A., \& Gallagher, M. (2008). Methodological immaturity in childhood research? Thinking through "participatory methods". Childhood, 15, 499-516.

Gallagher, M. (2008). "Power is not an evil": Rethinking power in participatory methods. Children's Geographies, 6, 137-150.

Gallagher, M. (2009). Ethics. In E. K. M. Tisdall, J. Davis, \& M. Gallagher (Eds.), Researching with children and young people: Research design, methods and analysis. London: SAGE Publications Ltd.

Goffman, E. (1959). The presentation of self in everyday life. New York: Anchor Books.

Graham, A., Powell, M. A., \& Taylor, N. (2015). Ethical research involving children: Encouraging reflexive engagement in research with children and young people. Children \& Society, 29, 331-343.

Graham, A., Powell, M. A., Taylor, N., Anderson, D., \& Fitzgerald, R. (2013). Ethical research involving children, Florence: UNICEF Office of ResearchInnocenti.

Hadfield-Hill, S., \& Horton, J. (2013). Children's experiences of participating in research: Emotional moments together? Children's Geographies, 1-19.

Hampshire, K., Porter, G., Owusu, S., Mariwah, S., Abane, A., Robson, E., . . B Bourdillon, M. (2012). Taking the long view: Temporal considerations in the ethics of children's research activity and knowledge production. Children's Geographies, 10, 219-232.

Hart, R. (2008). Stepping back from "the ladder": Reflections on a model of participatory work with children. In: Reid, A., Jensen, B., Nikel, J. \& Simovska, V. (Eds.), Participation and learning. Dordrecht: Springer Netherlands.

Holland, S., Renold, E., Ross, N. J., \& Hillman, A. (2010). Power, agency and participatory agendas: A critical exploration of young people's engagement in participative qualitative research. Childhood, 17, 360-375.

Holloway, S. L., \& Valentine, G. (2000). Children's geographies: Playing, living, learning. New York: Routledge. Horgan, D., Forde, C., Martin, S., \& Parkes, A. (2017). Chil- dren's participation: Moving from the performative to the social. Children's Geographies, 15, 274-288.

Horton, J. (2008). A 'sense of failure"? Everydayness and research ethics. Children's Geographies, 6, 363-383.

James, A., Jenks, C., \& Prout, A. (1998). Theorizing childhood. Cambridge: Polity Press.

James, A., \& Prout, A. (1997). Constructing and reconstructing childhood: Contemporary issues in the sociological study of childhood. London: Falmer Press.

Jones, O. (2003). "Endlessly revisited and forever gone": On memory, reverie and emotional imagination in doing children's geographies. An "addendum" to "“To go back up the side hill": Memories, imaginations and reveries of childhood" by Chris Philo. Children's Geographies, 1, 25-36.

Kellett, M. (2004). Just teach us the skills please, we'll do the rest: Empowering ten-years-olds as active researchers. Children \& Society, 18, 329-343.

Kellett, M. (2005). How to develop children as researchers: A step-by-step guide to teaching the research process. London: Sage.

Kellett, M. (2011). Empowering children and young people as researchers: Overcoming barriers and building capacity. Child Indicators Research, 4, 205-219.

Kim, C.-Y. (2016). Why research "by" children? Rethinking the assumptions underlying the facilitation of children as researchers. Children \& Society, 30, 230-240.

Leonard, M. (2016). The sociology of children, childhood and generation. London: Sage.

Liggins, J., Kearns, R. A., \& Adams, P. J. (2013). Using autoethnography to reclaim the "place of healing" in mental health care. Social Science \& Medicine, 91, 105-109.

Lundy, L., \& McEvoy, L. (2012). Children's rights and research processes: Assisting children to (in)formed views. Childhood, 19, 129-144.

Marsh, J. (2012). Children as knowledge brokers of playground games and rhymes in the new media age. Childhood, 19, 508-522.

Matthews, H. (2001). Power games and moral territories: Ethical dilemmas when working with children and young people. Ethics, Place \& Environment, 4, 117-118.

McLaughlin, H. (2005). Young service users as coresearchers: Methodological problems and possibilities. Qualitative Social Work, 4, 211-228.

Merryweather, D. (2016). Conference: Children and young people in a changing world. Action, agency and participation. Retrieved from http:// www.hope.ac.uk/childrenandyoungpeople

Mills, S. (2017). Voice: Sonic geographies of childhood. Children's Geographies, 1-14.

Mistry, J., Bignante, E., \& Berardi, A. (2016). Why are we doing it? Exploring participant motivations within a participatory video project. Area, 48, 412-418.

Morrow, V., \& Richards, M. (1996). The ethics of social research with children: an overview. Children \& Society, 10, 90-105. 
Nairn, K., Higgins, J., \& Sligo, J. (2007). Youth researching youth: "Trading on" subcultural capital in peer research methodologies. Teachers College Record, 109, 1-16.

Nespor, J. (1998). The meanings of research: Kids as subjects and kids as inquirers. Qualitative Inquiry, 4, 369-389.

Nielsen, H. B. (2016). The arrow of time in the space of the present: Temporality as methodological and theoretical dimension in child research. Children \& Society, 30, 1-11.

Nind, M. (2011). Participatory data analysis: A step too far? Qualitative Research, 11, 349-363.

Oldfather, P. (1995). Songs "come back most to them": Students' experiences as researchers. Theory into Practice, 34, 131-137.

Philo, C. (2003). "To go back up the side hill": Memories, imaginations and reveries of childhood. Children's Geographies, 1, 7-23.

Pinter, A., \& Zandian, S. (2012). "I thought it would be tiny little one phrase that we said, in a huge big pile of papers": Children's reflections on their involvement in participatory research. Qualitative Research, 15, 235-250.

Porter, G., Hampshire, K., Bourdillon, M., Robson, E., Munthali, A., Abane, A., \& Mashiri, M. (2010). Children as research collaborators: Issues and reflections from a mobility study in sub-Saharan Africa. American Journal of Community Psychology, 46, 215-227.

Porter, G., Townsend, J., \& Hampshire, K. (2012). Editorial: Children and young people as producers of knowledge. Children's Geographies, 10, 131-134.

Powell, M. A., Fitzgerald, R., Taylor, N., \& Graham, A. (2012). International literature review: Ethical issues in undertaking research with children and young people. Lismore and Dunedin: Southern Cross University, Centre for Children and Young People and University of Otago, Centre for Research on Children and Families.

Punch, S. (2002). Research with children: The same of different from research with adults? Childhood, 9, 321-342.

Rose, G. (1997). Situating knowledges: Positionality, reflexivities and other tactics. Progress in Human Geography, 21, 305-320.
Schäfer, N., \& Yarwood, R. (2008). Involving young people as researchers: Uncovering multiple power relations among youths. Children's Geographies, 6, 121-135.

Shaw, J. (2016). Emergent ethics in participatory video: Negotiating the inherent tensions as group processes evolve. Area, 48, 419-426.

Skelton, T. (2007). Children, young people, UNICEF and participation. Children's Geographies, 5, 165-181.

Smith, R., Monaghan, M., \& Broad, B. (2002). Involving young people as co-researchers: Facing up to the methodological issues. Qualitative Social Work, 1, 191-207.

Spyrou, S. (2015). Researching children's silences: Exploring the fullness of voice in childhood research. Childhood.

Thorne, B. (2002). Editorial: From silence to voice: Bringing children more fully into knowledge. Childhood, 9, 251-254.

Tisdall, E. K. M. (2012). The challenge and challenging of childhood studies? Learning from disability studies and research with disabled children. Children \& Society, 26, 181-191.

UNICEF. (1995). United Nations convention on the rights of the child. Retrieved from http://www.unicef.org/ crc

Uprichard, E. (2008). Children as "being and becomings": Children, childhood and temporality. Children \& Society, 22, 303-313.

Van Blerk, L., \& Kesby, M. (Eds.). (2013). Doing children's geographies methodological issues in research with young people. Hoboken: Taylor and Francis.

Von Benzon, N. (2015). "I fell out of a tree and broke my neck": Acknowledging fantasy in children's research contributions. Children's Geographies, 13, 330-342.

Walsh, S. (2016). Critiquing the politics of participatory video and the dangerous romance of liberalism. Area, 48, 405-411.

Weil, S. (1999). Recreating universities for "beyond the stable state": Drom "Dearingesque" systemic control to post-Dearing systematic learning and inequiry. Journal of Systems Research and Behavioural Science, 11, 171-190.

Wyness, M. (2013). Children's participation and intergenerational dialogue: Bringing adults back into the analysis. Childhood, 20, 429-442.

\section{About the Author}

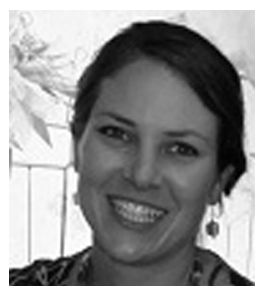

Christina Ergler is a lecturer in Social Geography at the University of Otago, New Zealand. Her research interests are at the intersection of geography, sociology and public health, and they centre on socio-spatial inequalities, experiential dimensions of health and wellbeing and participatory research methods. Dr. Ergler is interested in creating and applying creative, value-based, ethically and culturally appropriate methodologies that acknowledge the expertise of everyone and foster a meaningful participation in research activities. 